Sergio A. Albeverio - Raphael J. Høegh-Krohn Sonia Mazzucchi

\title{
Mathematical Theory \\ of Feynman Path Integrals
}

\section{An Introduction}

2nd corrected and enlarged edition

贶 Springer 


\section{Contents}

Preface to the Second Edition $\ldots \ldots \ldots \ldots \ldots \ldots \ldots \ldots \ldots, \mathrm{V}$

Preface to the First Edition $\ldots \ldots \ldots \ldots \ldots \ldots \ldots \ldots \ldots \ldots$ VII

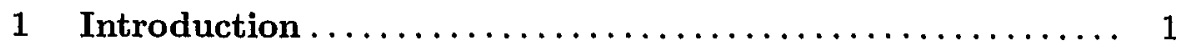

2 The Fresnel Integral of Functions on a Separable Real Hilbert Space $. \ldots \ldots \ldots \ldots \ldots \ldots \ldots \ldots \ldots \ldots \ldots, 9$

3 The Feynman Path Integral in Potential Scattering ....... 19

4 The Fresnel Integral Relative to a Non-singular Quadratic

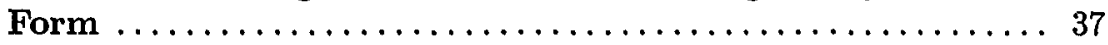

5 Feynman Path Integrals for the Anharmonic Oscillator .... 51

6 Expectations with Respect to the Ground State of the Harmonic Oscillator . . . . . . . . . . . . . . . . . . 63

7 Expectations with Respect to the Gibbs State of the Harmonic Oscillator...................... 69

8 The Invariant Quasi-free States .................. 73

9 The Feynman History Integral for the Relativistic Quantum Boson Field ............ 85

10 Some Recent Developments.................... 93

10.1 The Infinite Dimensional Oscillatory Integral........... 93

10.2 Feynman Path Integrals for Polynomially Growing Potentials ........................... 101

10.3 The Stationary Phase Method and the Semiclassical Expansion .............................. 108 
X Contents

10.4 Alternative Approaches to Rigorous Feynman

Path Integrals............................... 115

10.4.1 Analytic Continuation ..................... 115

10.4.2 White Noise Calculus Approach ............... 116

10.4.3 The Sequential Approach .................... 120

10.4.4 The Approach via Poisson Processes . . . . . . . . . 123

10.5 Recent Applications . . . . . . . . . . . . . . . . . . 124

10.5.1 The Schrödinger Equation with Magnetic Fields ....... 124

10.5.2 The Schrödinger Equation with Time Dependent

Potentials ............................. 125

10.5.3 Phase Space Feynman Path Integrals . . . . . . . . . 130

10.5.4 The Stochastic Schrödinger Equation ............. 133

10.5.5 The Chern-Simons Functional Integral ........... 136

References of the First Edition $\ldots \ldots \ldots \ldots \ldots \ldots \ldots \ldots \ldots \ldots \ldots \ldots$

References Added for the Second Edition ................ 149

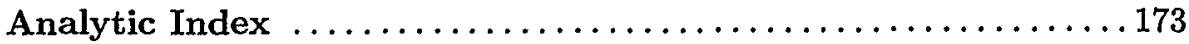

List of Notations $\ldots \ldots \ldots \ldots \ldots \ldots \ldots \ldots \ldots \ldots \ldots \ldots \ldots \ldots \ldots$ 